\title{
Temporal Changes in Biological Communities Affecting Models for Evaluating of Ecological Status
}

\author{
Simona Littnerová and Jiří Jarkovský \\ Institute of Biostatistics and Analyses, Masaryk University, Kamenice 3, Brno
}

\begin{abstract}
Temporal changes in the structure of biological communities are one of the factors affecting water quality assessment systems. The aim of our work was to analyze the temporal variability of benthic macroinvertebrates and its consequences for the established streams typology. The data analyzed come from a biomonitoring of streams of the Czech Republic during 2002-2005. Changes of the structure of macroinvertebrates communities were observed using diversity indices (Shannon index) and biotic indices (saprobic index) and using actual changes in community structure. The time related shift in indices and the community composition was found, but the correlation of the locality typologies and the change was not found.
\end{abstract}

\section{Introduction}

The most important process in communities we can rate is variation in species caused by extinction and colonization [1]. Dynamics of extinction and colonization can also affect the response of communities to environmental change, potentially leading to weakly predictable patterns of communities structure [2]. Therefore, understanding the influence of temporal variation on community structure and communityenvironment relationships is very important for predicting community distribution along environmental gradients. Current predictive models used in bioassessment mostly rely on single-surveys. We assume that results from single-surveys are representative of local community. The next assumption is that communities were stable in time [3]. However, in reality, the temporal dynamics of local community may swamp any general patterns [4].

The stability of habitat and interactions between species in community are the main factor, which have influence on temporal variability in community structure [5]. From this viewpoint the stream communities should be more studied, because they are highly variable in response to changes in environments. However, the relatively few studies are interested in temporal variability in streams. Their results are very controversial. Some studies have shown community structure to be relatively stable, especially if environmental conditions do not vary over time [6], [7], [8], whereas others have reported considerable temporal changes in community structure [9], [10], [11], [12].

In [6] were observed stable communities in 19 locations for 5 years. The authors have created for their data classification and ordination for each of the years and found that they are consistent in different years. They also created a model 
discriminating observations in the first year. This model predicted a correct group of invertebrates. Only for localities with riffles there was evidence of changes of communities that were subject to diminishing vegetation cover of banks.

Community of macroinvertebrates in the reference sites in remote areas of Idaho followed the authors in [7] for six years (1990-1995). Temporal changes of community environmental parameters were observed simultaneously. The authors stated that, despite changes in environmental conditions, caused mainly by climate change, there were only small changes in community structure, and thus could be regarded as stable community.

Also in [8] monitored community could be considered stable. The authors had 6year time series for 26 sites. Changes in environmental conditions were indeed statistically significant, but the link between changing environmental conditions and changing communities was very weak. Although communities were very different in different places, the overall change in community structure between years was not statistically significant. The authors also stated that it was followed by inter-season changes in communities.

On the other hand, other studies showed considerable change in communities over time. [9] watched the 27 rivers in southern England, whether they differ between year 1976 and 1984 in terms of macroinvertebrates and if this change is related to the variation of environmental conditions. The study examined whether the 15 most abundant species in 1976 occurred in 1984. The authors stated that among the surveyed year is great variability in temperature, $\mathrm{pH}$ and flow. With these changes also explained the structure of communities. Nevertheless the study reported that despite explanation the change in community structure with environmental parameters, community composition is hardly predictable.

Also in [10] there were significant community changes. In this study, the authors had available a very long time series ( 20 years). The 17 sites on two rivers in Australia were monitored. The authors focused on the structure of communities at the family and species level. At the family level the authors did not observed statistically significant changes over time, while at a more detailed level of species the change of community structure was significant. The authors discuss which units of biological classification to use, family or more detailed species. There was found that at the family level the temporal change may not always be detectable. Also, the author argues that it is not clear that the variability of community structure is related to changes of climate. Therefore a change in the community may not directly respond to climate change.

The study [11] observed influence of changes in environmental conditions on the change of macroinvertebrates in the river Rhone in France. It observed temporal change at the nine sites that were sampled from 1985 to 2004. During this period dry season (2003) occurred in the monitored area, caused by climate change. In this study, the authors used Procrustean analysis. The method discovered to what extent the environmental conditions are associated with the communities. The result was that the environmental conditions and macroinvertebrates communities change over time and changing community is strongly associated with variation of environmental conditions.

A very comprehensive study, which studied the temporal change of community and due to this change in the typology, is [12]. The study examined how much the 
general models were based on sampling from one year. In the work were used 34 localities in the north of Finland, which have been studied for three years (20012003). In this study, three tasks have been solved. First, what was the temporal variability in the community classification? For each year was established typology of communities. By the method Meansim was given the value of the classification strength (CS) for each year. The second task was to determine changes in temporal variability of relationships community-environment. Here the authors used discriminant analysis to determine the significance of environmental parameters for classification. A third task was to detect changes among communities in different years. Here Procrustean analysis was used and the related ProTest, which calculates the statistical significance of the compliance in community. It was found that communities in different years are different. The result of this study was that the classification of the different years is statistically significantly different and that during the monitored period, the composition of the groups formed by the classification changed. In terms of the relationships community-environment the change of community was penalized by vegetation cover of banks.

For conservation and bioassessment of streams is important to know temporal variability in community structure. Predictive models use biological and environmental data to model community-environmental relationships, with the aim predicting of biodiversity patterns. In streams, benthic macroinvertebrates are often used.

The aim of our work was to analyze the temporal variability of macroinvertebrates and its consequences for the established typology of streams.

\section{Study Area}

The data analyzed come from a biomonitoring of streams of the Czech Republic during 1996-2007. The data consists of two parts: reference and non-reference localities. On the basis of reference localities classifications were defined, abiotic and biotic. These were used in further analyses. To obtain the time series we selected localities with the complete record of the time period 2002-2005, 261 sites were selected. Changes in the structure of communities were observed between 2002-2003, 2002-2004 and 2002-2005 (Figure 1.). These were non-reference AWMA (Agricultural Water Management Authority) localities, mostly found in middle altitude with the rivers order 3-4. Predominant areas were from central Bohemia and in the nearest surroundings of the selected streams were the agriculture areas.

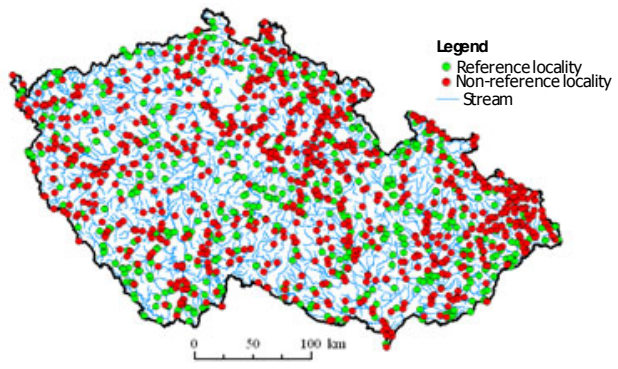

Fig. 1. Observed localities 


\section{Statistical Methods}

Standard descriptive statistics was used for the analysis. Several multivariate statistical methods were used too.

Changes were observed in terms of both diversity indices and biotic indices describing the community and in the terms of actual changes in community composition.

The first were created univariate categorizations based on environmental parameters. Next cluster analysis was used to create abiotic and biotic typologies. Both were produced on reference localities. Cluster analysis for abiotic classification was run on ln-transformed data of environmental parameters. The clustering algorithm Complete linkage was used for abiotic classification; biotic classification was computed using association matrix based on Jaccard coefficient of species distribution on sites. Optimal numbers of clusters were assessed by combination of Silhouette validation method, Meansim (Analysis of Similarity; [13]) and discrimination analysis. Non-reference localities were put into clusters by using discriminant analysis. Changes were observed in terms of both diversity and biotic indices and describing the community in terms of actual changes in community composition. Subsequently was tested whether the typologies of sites has an impact beyond this change; tested was the typology used in various types of assessment models of ecological status. To determine the indices changes over time and within types of sites was used RM ANOVA, for change in community Procrustean analysis [12], [14], [15], [16] followed by detailed analysis of temporal changes of individual taxa.

The Procrustean analysis is prior ordination methods. The aim of Procrustean analysis is measure of association between two ordinations. The method of Procrustean fitting is based on least-square criterion, which minimizes the sum of squared residuals between these two configurations. The results of Procrustean analysis is that every locality have two representations, from every matrix one. The simplified scheme used in this study is in Figure 2.

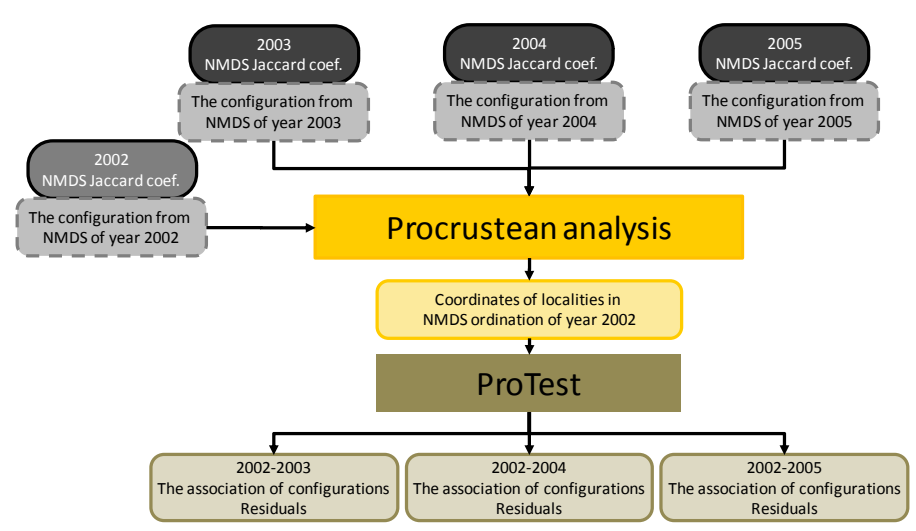

Fig. 2. The scheme of Procrustean analysis computation used in this study 
Computationally, the Procrustean fit can be achieved in two steps: (1) centering and scaling:

$$
\mathbf{X}_{\text {scl }}=\frac{(\mathbf{I}-\mathbf{P}) \mathbf{X}}{\sqrt{\operatorname{tr}\left((\mathbf{I}-\mathbf{P}) \mathbf{X}^{\mathrm{T}}(\mathbf{I}-\mathbf{P})\right)}}
$$

$\mathbf{X}$ is reference configuration, $\mathbf{I}$ is $(\mathbf{n} \times n)$ identical matrix, $\mathbf{P}$ is $(\mathbf{n} \times n)$ matrix with all elements $=1 / n$. Repeated this step for configuration $\mathbf{Y}$ we obtain $\mathbf{Y}_{\text {scl }}$. Note that the scaling process do not change variance of variables, so that variables with have high variances originally will have more importance in the overall fit. This problem can be eliminated by standardization of variables; (2) Reflection, rotation and the residual sum-of-squares statistics:

$$
m_{12}^{2}=2(1-\operatorname{Tr} \mathbf{W})
$$

$\mathbf{W}$ is obtained by the singular value decomposition

$$
\left(\mathbf{X}_{\text {scl }}^{\mathrm{T}} \mathbf{Y}_{\text {scl }}\right)=\mathbf{V W} \mathbf{U}^{\mathrm{T}}
$$

The value of $m_{12}^{2}$ vary between the range of 0 and 1 .

The optimal rotation matrix (that providing the best fit) can be calculated as

$$
\mathbf{H}=\mathbf{U V}^{\mathrm{T}} \text {. }
$$

The $m_{12}^{2}$ can also be calculated by first rotating the matrix $\mathbf{Y}$

$$
\mathbf{Y}_{\text {rot }}=\mathbf{Y}_{\text {scl }} \mathbf{H} \text {. }
$$

and then finding the sum of the squared distances between $\mathbf{X}_{\text {scl }}$ and $\mathbf{Y}_{\text {rot }}$. Note that where $\mathrm{X}$ and $\mathrm{Y}$ have only one variable each, $\mathbf{W}$ is equal to the Pearson correlation index and therefore.

$$
m_{12}=1-r^{2} .
$$

The superimposition process requires that matrices have same dimension, where this is not, the matrix with smaller number of variables can be filled with vectors of zeros until it has the same dimension as the larger matrix.

Statistical significance of Procrustean fit $\left(m_{12}^{2}\right)$ was assumed by a permutation test ProTest.

Prior procrustean analysis was used non-metric multidimensional scaling (NMDS) ordination based on Jaccard coefficient to summarize communities structure in each study year.

ProTest provides vector of residuals for every sample. These residuals present difference in the position of individual sample between superimposed ordinations. The length of residuals is lack of fit for an individual sample in between ordinations. It corresponds to change of community structure on each locality between time points. To determinate the influence of categorizations and typologies on residuals was used one-way ANOVA. 
Afterwards were observed if vectors of residuals were related to change of chemical parameters. The associations between residuals and change of chemical parameters were assessed by Spearmans correlation coefficient. This analysis was only supplementary, because time series of chemical parameters had incomplete records (190 localities).

PASW Statistics 18 for Windows (Release 18.0.0, (C) SPSS Inc. 2009) was used for descriptive data analysis. Procrustean analysis was computed by software R ( R version 2.10.1 (2009-12-14),Copyright (C) 2009 The R Foundation for Statistical Computing). For Meansim analysis was used software MEANSIM MEANSIM, Version 6.0 (http://www.epa.gov)

The map was created by ArcMap 9.2 (build 1324, (c) 1999-2006 ESRI Inc).

\section{Results}

The changes of indices were found in years and season (Table 1). Both of indices (Shannon and saprobic) changed in years, under seasons was observed statistically significant difference only in saprobic index, the change in Shannon index not. The influence of the typology on this change was found in years, but in interaction of time and typologies was not found.

Table 1. Value of Shannon and saprobic index for spring and fall

\begin{tabular}{|c|c|c|c|c|c|}
\hline & & 2002 & 2003 & 2004 & 2005 \\
\hline \multirow{2}{*}{$\frac{\infty}{\stackrel{5}{\vdots}}$} & $\begin{array}{c}\text { Shannon } \\
\text { index }\end{array}$ & $\begin{array}{c}2.09 / 2.13 \\
(0.98 ; 3.06)^{1}\end{array}$ & $\begin{array}{c}1.70 / 1.76 \\
(0.71 ; 2.72)\end{array}$ & $\begin{array}{c}1.73 / 1.73 \\
(0.53 ; 2.76)\end{array}$ & $\begin{array}{c}2.1 / 2.14 \\
(0.95 ; 3.16)\end{array}$ \\
\hline & $\begin{array}{c}\text { Saprobic } \\
\text { index }\end{array}$ & $\begin{array}{c}2.21 / 2.22 \\
(1.32 ; 3.33) \\
\end{array}$ & $\begin{array}{c}2.32 / 2.30 \\
(1.43 ; 3.34) \\
\end{array}$ & $\begin{array}{c}2.37 / 2.42 \\
(1.34 ; 3.44)\end{array}$ & $\begin{array}{r}2.34 / 2.30 \\
(1.48 ; 3.49) \\
\end{array}$ \\
\hline \multirow[t]{2}{*}{$\underset{\mathbb{z}}{\vec{x}}$} & $\begin{array}{c}\text { Shannon } \\
\text { index }\end{array}$ & $\begin{array}{c}1.93 / 1.98 \\
(0.50 ; 2.90)\end{array}$ & $\begin{array}{c}1.90 / 1.99 \\
(0.74 ; 2.81)\end{array}$ & $\begin{array}{c}1.83 / 1.93 \\
(0.41 ; 2.76)\end{array}$ & $\begin{array}{c}2.11 / 2.18 \\
(1.03 ; 3.00)\end{array}$ \\
\hline & $\begin{array}{c}\text { Saprobic } \\
\text { index }\end{array}$ & $\begin{array}{c}2.25 / 2.18 \\
(1.50 ; 3.54)\end{array}$ & $\begin{array}{c}2.45 / 2.32 \\
(1.55 ; 3.76)\end{array}$ & $\begin{array}{c}2.42 / 2.28 \\
(1.54 ; 3.70)\end{array}$ & $\begin{array}{r}2.38 / 2.31 \\
(1.60 ; 3.60)\end{array}$ \\
\hline
\end{tabular}

Table 2. Conclusion of ProTest. Statistical significance of Procrustean fit

\begin{tabular}{cccc}
\hline Comparison & $\mathbf{m}$ & $\mathbf{m}^{2}$ & Sig. \\
\hline $\mathbf{2 0 0 2}$ and $\mathbf{2 0 0 3}$ & 0.512 & 0.262 & $<0.01^{*}$ \\
$\mathbf{2 0 0 2}$ and $\mathbf{2 0 0 4}$ & 0.518 & 0.268 & $<0.01^{*}$ \\
$\mathbf{2 0 0 2}$ and 2005 & 0.447 & 0.200 & $<0.01^{*}$ \\
\hline
\end{tabular}

Afterward was observed change of community structure by Procrustean analysis. It was compared structure of community from year 2002 with years 2003-2005. The ProTest, with 999 permutations, assessed statistical significance of ordination fit, 
from Table 2. It is obvious that associations for each individual pair of ordination are statistically significant. But the associations were not significant, therefore the changes between ordinations in time were observed. The considerable change was recorded between 2002 and 2003 (Table 2). This change is a possible consequence of high precipitation in 2002. The effect of this change on typology was not found.

The result of Procrustean analysis was positions of localities from ordinations from years 2003-2005 in ordinations from year 2002 (Figure 3). The distances between localities in different years in Figure 3 can be understood as measure of community change.

Thanks to gained values of chemical parameters for several localities was possible to assess relationships between change of chemical parameters and Procrustean residuals. Complementary calculations it was found that the change is linked to the biological oxygen demand.

In conclusion temporal changes of biotic indices and community structure were observed, but relationship between the change and typology was not established. Changes in community structure could be related to biological oxygen demand and change of nutrients volume.

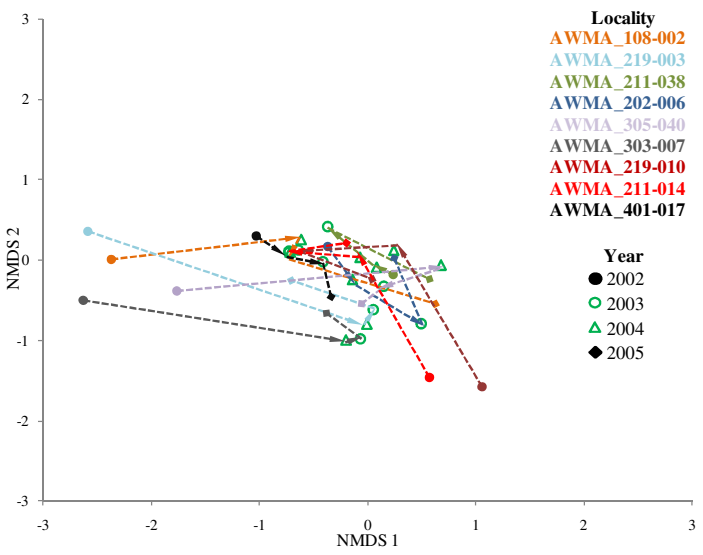

Fig. 3. Positions of nine the most changing localities. In ordination from year 2002 there were represented positions of localities from other years.

\section{Conclusion}

Predictive models of ecological status are based on relationship communityenvironment. Therefore understanding of variability in these relationships is a critical aspect of the utility of these models. Yet models assume that communities are stable over time.

First time were monitored indices describing the communities, saprobic and Shannon index. Here it was found that the indices changes over time, but the typology does not follow the changes in these indices, except groups of altitude for saprobic 
index and type of hydroecoregion for saprobic and Shannon index. Nevertheless, we can say that time changes in indices are consistent in each categorization of localities.

Temporal variability of community structure was also studied by Procrustean analysis and ProTest. It was observed that the communities of the years 2003, 2004 and 2005 differ from the community from the initial 2002. Here it was found that the change from the initial year is considerable. Communities of individual sites in different years were compared using Jaccard index, this confirmed a considerable change among the communities in surveyed years. The Procrustean analysis made a vector of residuals, which represent the distance from the site one year-another year, which means similarity between sites in two time points. The analysis of these residuals was used to determine whether classifications were influenced by the magnitude of the change. The result was that the classification does not affect the levels of residuals. Therefore, the community has changed over time, but in all the categorization by analogy. The complementary calculation, available for several localities, found that the change is linked to the biological oxygen demand.

\section{References}

1. Lomolino, M.V., Riddle, B.R., Brown, J.H.: Biogeography, 3rd edn. Sinauer asociates, Sunderland (2006)

2. Ozinga, W.A., Schaminee, J.H.J., Bekker, R.M., Bonn, S., Poschlod, P., Tackenberg, O., Bakker, J., van Groenendael, J.M.: Predictability of plant species composition from environmental conditions is constrained by dispersal limitation. Oikos 108, 555-561

3. Bunn, S.E., Davies, P.M.: Biological processes in running waters and their implications for the assessment of ecological integrity. Hydrobiologia 422, 61-70 (2000)

4. Olden, J.D., Jensen, O.P., Vander Zanden, M.J.: Implications of long-term dynamics of fish and zooplankton communities for among-lake comparisons. Canadian Journal of Fisheries and Aquatic Sciences 63, 1812-1821 (2006)

5. Oberdorff, T., Hugueny, B., Vigneron, T.: Is assemblage variability related to environmental variability? An answer for riverine fis. Oikos 93, 419-428 (2001)

6. Weatherley, N.S., Ormerod, S.J.: The constancy of invertebrate assemblages in soft-water streams: implications for the prediction and detection of environmental change. Journal of Applied Ecology 27, 952-964 (1990)

7. Robinson, C.T., Minshall, G.W., Royer, T.V.: Inter-annual patterns in macroinvertebrate communities of wilderness streams in Idaho, USA. Hydrobiologia 421, 187-198 (2000)

8. Scarsbrook, M.R.: Persistence and stability of lotic invertebrate communities in New Zealand. Freshwater Biology 47, 417-431 (2002)

9. Townsend, C.R., Hidrew, A.G., Schofield, K.: Persistence of stream invertebrate communities in relation to environmental variability. Journal of Animal Ecology 56, 597 613 (1987)

10. Metzeling, L., Robinson, D., Perriss, S., Marchant, R.: Temporal persistence of benthic invertebrate communities in south-eastern Australian streams: taxonomic resolution and implications for the use of predictive models. Marine and Freshwater Research 53, 1223 1234 (2002)

11. Daufresne, M., Bady, P., Fruget, J.F.: Impacts of global changes and extreme hydroclimatic events on macroinvertebrate community structures in the French Rhone River. Oecologia 151, 544-559 (2007) 
12. Mykrä, H., Heino, J., Muotka, T.: Concordance of stream macroinvertebrate assemblage classifications: How general are patterns from single-year surveys? Biological conservation (2008), doi:10.1016/j.biocon.2008.02.017

13. Van Sickle, J., Hughes, R.M.: Classification strengths of ecoregions, catchments, and geographic clusters for aquatic vertebrates in Oregon. Journal of The North American Benthological Society 19, 370-384 (2000); Smith, T.F., Waterman, M.S.: Identification of Common Molecular Subsequences. J. Mol. Biol. 147, 195-197 (1981)

14. Peres-Neto, P.R., Jackson, D.A.: How well do multivariate data sets match? Evaluating the association of multivariate biological data sets: comparing the robustness of Mantel test and a Procrustean superimposition approach. Oecologia 129, 169-178 (2001)

15. Jackson, D.A.: ProTest: a Procrustean randomization test of community environment concordance. Ecoscience 2, 297-303 (1995)

16. Legendre, P., Legendre, L.: Numerical Ecology, 2nd Engl. edn. Elsevier, Amsterdam (1998) ISBN 0444892494 